\title{
The BMJ and its plans
}

\author{
Fiona Godlee editor in chief, The BMJ
}

One UK reader, and perhaps others, didn't like the Essay we published from the United States on "flipping healthcare" (doi:10.1136/bmj.g5852). "What does a country that spends a staggering $18 \%$ of gross domestic product on healthcare-yet has the same life expectancy and worse infant mortality than Cuba-have to teach others on this subject," writes Nikolai Manassiev in a letter this week (doi:10.1136/bmj.g6847). Other respondents were more positive about the article, but Manassiev goes on to slam The BMJ. "The fact that this paper is not just published, but is given the same space as research plus a mention on the cover, tells me about the difficulties The BMJ has in attracting credible research and reviews and how shallow it has become."

The BMJ revels in criticism. Perhaps because of that, we have, by general assent, the most active online letters (rapid responses) of any medical journal, and we continue to be grateful to readers for engaging with us and our authors in this way. What's more, the views expressed in this particular letter are likely to be shared by other UK doctors who read mainly or only the print journal. It shows that we have some explaining to do about our direction of travel and our plans for the future.

The $B M J$ is an international journal. Our aim is to improve health and healthcare internationally and to help doctors make better decisions wherever they are in the world. It's an ambitious, some may say unrealistic, goal. But we are not discouraged, because The BMJ is first and foremost a digital journal. All our content-research, education, news, and comment—is online, and our new mobile enabled website, with its channels for different regions of the world, means that this rich mix of content can be viewed easily on various devices.

Still, print matters to us. Many readers access The BMJ in print and want to continue to do so. We have an especially large print readership in the UK, which we greatly value and for whom we want to provide stimulating and relevant content that helps readers in their working lives. Clearly, articles that might work online, to be accessed at choice by readers around the world, may not work so well when served up in a weekly print journal now largely targeted at UK readers. And, likewise, a print journal that aims to appeal to UK clinicians and is delivered to their homes for browsing at leisure cannot do justice to the large number of academic and internationally focused articles-research, analysis, in-depth clinical and methodological reviews - that we publish in full online.

We think we have a solution, which I outline here so as to get your feedback. Firstly, The BMJ will continue to grow online and internationally. We already have clinical and research staff in the US, Europe, Australia, and India, and over the next few years we will be looking to recruit editors and journalists in China, Latin America, the Middle East, and South East Asia, as our resources allow. Regional editorial boards will advise and guide us. Secondly, we are redesigning the weekly print magazine to reflect the latest in magazine design, with a focus on the needs of UK clinicians. Market research is under way, and the new design will be launched in the middle of next year. Thirdly, to enable this further development of our UK magazine, we are launching a new monthly international academic print journal for libraries and academic institutions. This will carry the full text of all research articles, academic comment, and clinical reviews and will properly showcase the full extent and quality of our authors' work. The iPad and apps for other devices will allow mobile e-readers to browse whichever print bundle they prefer.

Our hope is that this combination of options will allow readers to get what they need from The BMJ so that we can continue to challenge, inform, annoy, and entertain you, wherever you are in the world, and continue to get your responses.

Cite this as: BMJ 2014;349:g6970

๑ BMJ Publishing Group Ltd 2014 